\title{
ANALISIS PENERAPAN TARIF PROGRESIF DALAM UPAYA MENEKAN DWELLING TIME IMPOR DI PT. JAKARTA INTERNATIONAL CONTAINER TERMINAL
}

\author{
Winoto Hadi ${ }^{1}$, Dyah Puspitasari ${ }^{2}$ \\ 'Prodi D III Transportasi, Fakultas Teknik - UNJ \\ Prodi D III Transportasi, Fakultas Teknik - UNJ
}

\begin{abstract}
Abstrak. Tingginya dwelling time di pelabuhan menjadikan fungsi pelabuhan tidak sesuai. Dwelling time terdiri dari tiga komponen yaitu pre clearance, custom clearance, dan post clearance. Salah satu faktor tingginya dwelling time impor yaitu terdapat pada importir. Dwelling Time cenderung diatur oleh pengirim barang dan pada akhirnya memiliki kecenderungan untuk mengalami peningkatan. Sehingga kualitas layanan menjadi bukan satu-satunya faktor yang mempengaruhi dwellingi time, tetapi biaya penyimpanan di pelabuhan juga berkontribusi. Penerapan tarif progresif ini diharapkan dapat mengembalikan fungsi pelabuhan sebagai gerbang lalu lintas barang, bukan sebagai tempat menyimpan peti kemas. Penerapan tarif tersebut dapat dinilai konsekuensi dari barang yang ditumpuk lama di pelabuhan dan berharap agar dapat memberikan efek jera bagi pemilik barang impor untuk tidak berlama-lama menimbun peti kemas di kawasan lini satu pelabuhan.
\end{abstract}

Kata Kunci : tarif progresif, dwelling time, impor

\section{A. PENDAHULUAN}

Fungsi pelabuhan pada dasarnya merupakan tempat transit, sehingga petikemas yang masuk atau barang yang sudah selesai proses kepabeanannya dapat segera dikeluarkan. Sebagaimana yang tercantum dalam Peraturan Menteri Perhubungan No PM 25 Tahun 2017 yaitu lapangan penumpukan petikemas bukan merupakan tempat penimbunan barang tetapi sebagai area transit untuk menunggu pemuatan atau pengeluarannya.

Namun selama ini masih banyak petikemas yang ditumpuk di pelabuhan, padahal petikemas tersebut telah memiliki izin untuk dikeluarkan dari terminal namun para pemilik barang enggan mengambil petikemas nya dan berlama-lama ditumpuk diterminal. Hal ini terus berjalan secara efektif sehingga mengganggu kelancaran lalu lintas barang di pelabuhan yang pada akhirnya menyebabkan tingginya dwelling time. Lamanya peti kemas mengendap di lapangan lini 1 menjadikan fungsi pelabuhan tidak seusai dengan peruntukannya, hal ini dikarenakan oleh beberapa sebab utama, yang pertama adalah lamanya waktu proses pelayanan di pelabuhan, import container dwelling time memegang peranan penting karena berhubungan langsung dengan lama waktu yang harus dilalui dalam satu rangkaian proses pelayanan kepengurusan peti kemas di dalam terminal. Apabila permasalahan tersebut tidak segera diberikan langkah perbaikan maka akan sangat berdampak terhadap kelancaran kegiatan di lingkungan pelabuhan.

Untuk mampu mengakomodir kebutuhan akan kelancaran bongkar muat barang, sebagai operator Pelabuhan Tanjung Priok, PT Pelabuhan Indonesia II (Persero) atau Pelindo II terus berupaya dalam menekan dwelling time maka pemerintah menerapkan tarif progresif.

Penerapan tarif progresif ini diharapkan dapat mengembalikan fungsi pelabuhan sebagai gerbang lalu lintas barang, bukan sebagai tempat menyimpan peti kemas. Penerapan tarif progresif ini berharap agar dapat memberikan efek jera bagi pemilik barang impor untuk tidak berlama-lama menimbun peti kemas di kawasan lini satu pelabuhan. Karena pelabuhan menjalankan bisnis intinya sebagai pelayanan percepatan sandar kapal dan bongkar-muat barang bukan menjadi lokasi untuk penimbunan. 
B. KERANGKA BERFIKIR

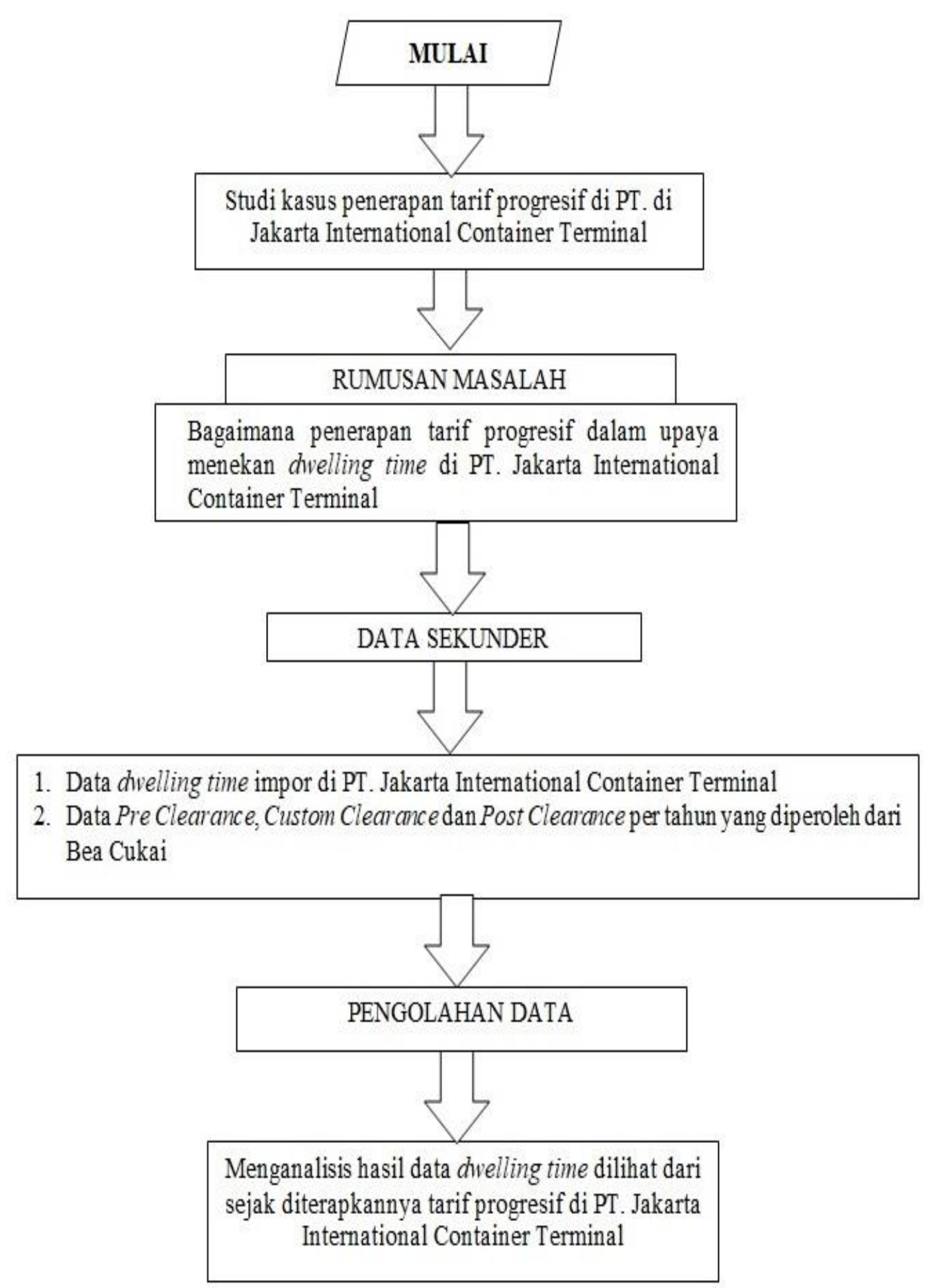




\section{LANDASAN TEORI}

\section{Tarif Progresif}

Menurut Mardiasmo (2009), Tarif Progresif yaitu persentase tarif yang digunakan semakin besar bila jumlah yang dikenai pajak semakin besar.

\section{Dwelling Time}

Definisi dwelling time yang digunakan Bank Dunia dalam Artakusuma (2012) adalah ukuran waktu yang dibutuhkan container impor, sejak container dibongkar dari kapal (berthing) sampai dengan keluar dari kawasan pelabuhan (gate out). Nicoll (2007) menjelaskan definisi dwelling time adalah "the amount of time that an import container sits at a marine terminal (terminal dwell time) or rail terminal (rail dwell time) before commencing its inland journey." Penjelasan ini dirujuk pula oleh Artakusuma dan diterjemahkan menjadi "lama waktu petikemas (container) berada di pelabuhan sebelum memulai perjalanan darat baik menggunakan truk atau kereta api."

\section{Komponen Dwelling Time}

Selama berada di pelabuhan, peti kemas mengalami berbagai proses seperti yang telah disebutkan di sub-bab sebelumnya. Secara garis besar proses yang menentukan lamanya import container dwelling time di pelabuhan adalah:

1. Pre-clearance

a. Peti kemas (kontainer) dibongkar dan diangkat dari kapal

b. Peti kemas diletakkan di tempat penimbunan sementara (TPS)

c. Penyiapan dokumen Pemberitahuan Impor Barang (PIB)

2. Customs clearance

a. Pemeriksaan fisik peti kemas (khusus untuk jalur merah)

b. Verifikasi dokumen-dokumen oleh Bea Cukai

c. Pengeluaran Surat Persetujuan Pengeluaran Barang (SPPB)

3. Post-clearance

a. Peti kemas (kontainer) diangkut oleh truk

b. Pembayaran ke operator pelabuhan

maka dwelling time impor dapat dihitung sebagai berikut:

$\mathrm{DT}=\mathrm{TP}+\mathrm{TCC}+\mathrm{TPC}$

$\mathrm{DT}=d$ welling time impor

$\mathrm{TP}=$ Lama waktu pre-clearance

TCC = Lama waktu customs clearance

$\mathrm{TPC}=$ Lama waktu post-clearance

\section{METODE PENELITIAN}

Penelitian ini dilakukan dengan cara deskriptif dan naratif. Metode pembahasan merupakan cara yang digunakan untuk memaparkan masalah pembahasan mengenai permasalahan yang dipilih.

\section{E. PEMBAHASAN}

\section{Penerapan Tarif Progresif}

Pemberlakuan tarif progresif di pelabuhan sebagai upaya untuk menurunkan waktu inap barang hingga keluar pelabuhan yang biasa disebut dengan waktu dwelling time. Sebelum dilakukan penerapan tarif progresif pada tanggal 1 maret 2016. Perubahan tarif ini bukan merubah tarif dasar tetapi hanya merubah tarif pinalti. Tarif dasar untuk petikemas isi impor 20 feet sebesar Rp. 27. 200 dan untuk petikemas isi impor 40 feet sebesar Rp. 54.400. Pemberlakuan tarif ini hanya diberlakukan di empat pelabuhan yaitu Pelabuhan Belawan (Medan), Pelabuhan Makassar, Pelabuhan Tanjung Perak (Surabaya) dan Pelabuhan Tanjung Priok.

Penerapan tarif progresif ini bertujuan agar barang yang menumpuk dipelabuhan tidak lebih dari tiga hari seperti aturan pemerintah dalam Permenhub No. 117 tahun 2015 tentang Pemindahan Barang yang Melewati Batas Waktu Penumpukan (Long Stay) di Pelabuhan Tanjung Priok. Aturan Permenhub ini menggantikan aturan sebelumnya yakni Permenhub NO. 807 tahun 2013, yang menyebutkan longstay selama tujuh hari. Penerapan tarif tersebut dapat dinilai 
konsekuensi dari barang yang ditumpuk lama di pelabuhan sehinga menghambat arus barang dan menambah $d w e l l i n g$ time.

Tarif yang digunakan sebelum penerapan tarif progresif:
a. Masa bebas (1-3 hari)
$=$ free
b. Masa II (4-10 hari)
$=500 \%$ x Tarif Dasar Penumpukan
c. Masa III (11- dst)
$=700 \%$ x Tarif Dasar Penumpukan

Adapun tarif progresif untuk impor yang dikenakan pada tanggal 1 maret 2016 adalah:

a. Hari ke-1 (ke-satu) tidak dipungut tarif pelayanan jasa penumpukan (free)

b. Hari ke-2 (ke-dua) dan seterusnya dihitung per hari besarnya sebesar $900 \%$ dari tarif dasar

Penerapan tarif tersebut dinilai oleh Asosiasi Logistik Indonesia sangat tinggi dan memberatkan para pelaku usaha dibandingkan dengan tarif sebelumnya. Sehingga banyak mendapatkan protes dan menolak pemberlakuan tarif tersebut. Karena hanya membebaskan tarif penumpukan petikemas pada hari pertama saja, tapi untuk hari kedua dan seterusnya terjadi kenaikan tarif perhari yaitu 900\% dari tarif dasar. Pemberlakuan pinalti sebesar 900\% tehadap petikemas impor mulai hari kedua cukup efektif dalam menekan dwelling time.

Kemudian di ubahlah tarif tersebut. Terhitung mulai tanggal 30 April 2016 mulai dikenakan tarif terbaru. Diharapkan dengan tarif terbaru ini tidak memberatkan para importir tetapi tidak juga Dengan tarif sebagai berikut:

a. Hari ke-1 (ke-satu) tidak dipungut tarif pelayanan jasa penumpukan (free)

b. Hari ke-2 (ke-dua) dihitung perharinya sebesar 300\% dari tarif dasar

c. Hari ke-3 (ke-tiga) dihitung perharinya sebesar $600 \%$ dari tarif dasar

d. Hari ke-4 (ke-empat) dan seterusnya dihitung perharinya $900 \%$ dari tarif dasar.

Presentasi biaya yang dikeluarkan

\begin{tabular}{|c|l|c|c|}
\hline No & Tarif & $\begin{array}{c}\text { Biaya yang } \\
\text { dikeluarkan }\end{array}$ & \multirow{2}{*}{$\begin{array}{c}\text { Presentase Kenaikan dan } \\
\text { Penurunan }\end{array}$} \\
\hline 1 & Tarif sebelum progresif & Rp. 272.000 & \multirow{2}{*}{ Kenaikan sebesar 260\% } \\
\cline { 1 - 2 } \cline { 2 - 2 } 3 & Tarif progresif 900\% & \multirow{2}{*}{ Rp. 979. 200 } & Penurunan sebesar 33\% \\
\hline & $\begin{array}{l}\text { Tarif progresif 300\%, 600\% dan } \\
900 \%\end{array}$ & Rp.734.400 & \\
\hline
\end{tabular}

Sumber: perhitungan yang sudah diolah

Berdasarkan tabel diatas, jumlah presentase kenaikan tarif progresif (tarif 900\%) meningkat sebanyak $260 \%$. Kenaikan ini cukup dinilai sangat berpengaruh terhapad para importir. Dikarenakan tarif yang mahal tersebut mengakibatkan para importir harus segera mengeluarkan barang dipelabuhan agar biaya yang dikeluarkan tidak semakin tinggi. Sedangkan pada tarif progresif kedua terjadi penurunan sebesar 33\%. Namun penurunan ini tidak terlalu berpengaruh dan dapat menstabilkan dwelling time tersebut. Tarif ini juga dirasa cukup adil sehingga tidak memberatkan pihak yang terkait yaitu importir. Karena dibandingkan dengan tarif sebelumnya biaya yang dikeluarkan lebih tinggi. Dari hasil analisis tersebut, penerapan tarif progresif berpengaruh dalam menekan dwelling time impor di PT. Jakarta International Container Terminal. Dapat dilihat pada Grafik 3.4

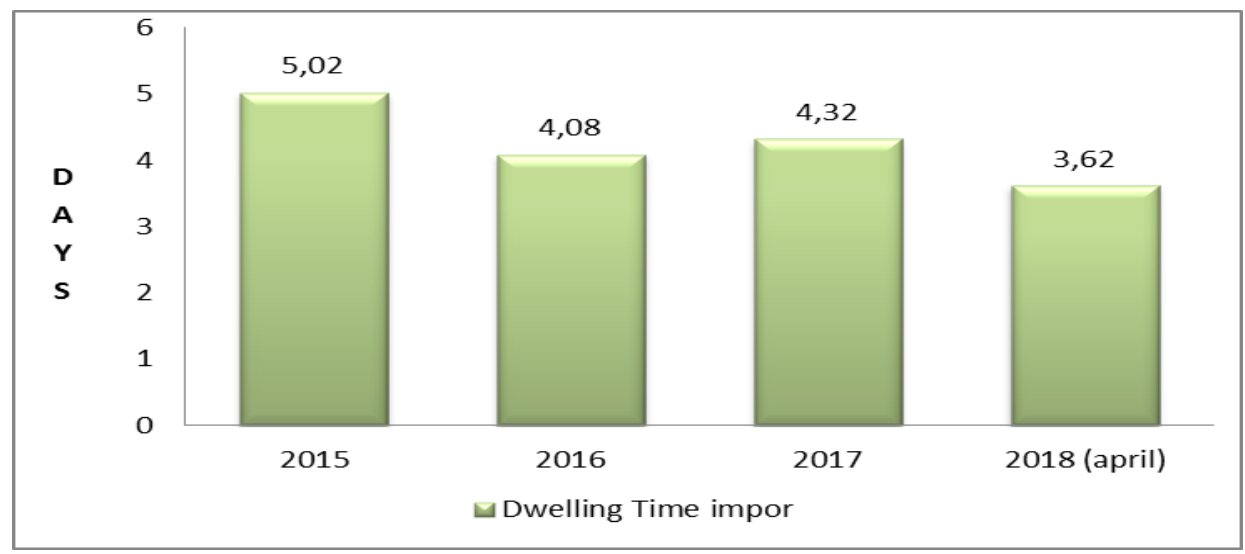

Gambar 3.4 Dwelling Time Impor di PT. JICT tahun 2015-2018

Sumber: Divisi Komersil JICT 
Dari grafik diatas dapat dilihat penerapan tarif progresif oleh pemerintah dimulai pada tahun 2016. Pada tahun tersebut dwelling time turun sampai dengan tahun 2018. Jadi dapat diketahui penerapan tarif progresif ini dapat menekan dwelling time impor di PT. Jakarta International Container Terminal. Namun masih terdapat beberapa importir yang masih menumpuk barangnya dipelabuhan.

Berdasarkan hasil perhitungan, lama waktu rata-rata dwelling time di JICT sudah mencapai 3,62 hari pada bulan April 2018. Menurut Menteri Perhubungan, Budi Karya Sumadi, dwelling time menjadi tolak ukur dalam pelayanan pelabuhan sehingga lama waktu container dwelling time ditetapkan tidak boleh melebihi 3 hari sebagai tolak ukur kecepatan arus barang. Maka apabila menggunakan waktu 3 hari sebagai tolak ukur tingkat pelayanan, maka tingkat pelayanan di JICT belum dapat dikategorikan baik karena masih melampaui 3 hari.

\section{F. KESIMPULAN}

Berdasarkan pengamatan dan pembahasan sebelumnya, didapatkan kesimpulan sebagai berikut:

1. Dwelling time terdiri dari tiga komponen yaitu pre clearance, custom clearance dan post clearance. Salah satu faktor yang mempengaruhi lamanya dwelling time impor yaitu karena pemilik barang / importir yang tidak segera mengeluarkan barangnya dari pelabuhan. Oleh karena itu pada tahun 2016, pemerintah menerapkan tarif progresif.

2. Penerapan tarif progresif di PT. Jakarta International Container Terminal cukup efektif dalam menekan $d w e l l i n g$ time dikarenakan dapat dilihat dari tahun 2015 lalu sejak tarif progresif tersebut diberlakukan sampai dengan tahun 2018 dwelling time impor menurun yaitu pada tahun 2015 sebesar 5,02 hari; tahun 2016 sebesar 4,08 hari; tahun 2017 sebesar 4,32 hari dan untuk tahun 2018 pada bulan April sebesar 3,62 hari.

3. Dengan pemberlakuan tarif progresif ini, kecenderungan para pemilik barang impor lebih cepat memproses pengeluaran barangnya. Sehingga aktivitas pelabuhan semakin lancar.

4. Besarnya dwelling time impor bulan April 2018 saat ini sudah lebih baik dibandingkan dengan tahun sebelumnya namun belum mencapai tolak ukur tingkat pelayanan di pelabuhan yaitu sebesar 3 hari sesuai dengan Permenhub No. 117 tahun 2015 tentang Pemindahan Barang yang Melewati Batas Waktu Penumpukan (Long Stay) di Pelabuhan Tanjung Priok.

5. Banyaknya faktor-faktor dan pihak-pihak yang terkait sehingga dwelling time belum mencapai angka tiga hari sesuai yang ditetapkan.

\section{G. SARAN}

Berdasarkan uraian diatas penulis memberikan beberapa saran yang mungkin dapat menjadi bahan pertimbangan oleh PT. Jakarta International Container Terminal yaitu:

1. Mensosialisasikan tarif progresif ke pelaku usaha khususnya importir agar tidak berlama-lama menumpuk barangnya dipelabuhan

2. PT. Jakarta International Container Terminal perlu melakukan kajian lebih dalam lagi terhadap penerapan tarif progresif agar dwelling time tidak lebih dari tiga hari sesuai dengan Permenhub No. 117 tahun 2015 tentang Pemindahan Barang yang Melewati Batas Waktu Penumpukan (Long Stay) di Pelabuhan Tanjung Priok.

3. Mengkaji lebih dalam faktor-faktor apa sajakah yang mempengaruhi beberapa importir yang masih sering menumpuk barangnya di pelabuhan.

4. Melakukan penelitian bersama dengan pemerintah tentang kebijakan tarif progresif tersebut sudah sesuai dengan para pelaku usaha atau belum. Jika dirasa belum maka perlu dilakukan penelitian untuk mengubah kebijakan tarif progresif tersebut.

\section{H. DAFTAR PUSTAKA}

1. Bowersox,Donald J. 1978. Manajemen Logistik:Integrasi Sistem-Sistem Manajemen Distribusi Fisik dan Manajemen Material(terjemahan Drs.A.Hasymi Ali). Jakarta:Penerbit Bumi Aksara.

2. Purnomo,Hari.2004.Perencanaan dan Perancangan Fasilitas.Edisi Pertama,Yogyakarta: Graha Ilmu.

3. Suyono,M.Mar,R.P,Capt.2005.Shipping: Pegertian, Jenis dan Fungsi Gudang

4. Warman,John.2004.Manajemen Pergudangan.Jakarta: CV.Mulyasari 
